\title{
TOUSSAINT EN LAS LETRAS
}

\section{$\mathbf{P} \mathbf{O}$}

\section{JOSE ROJAS GARCIDUE T̃ S}

H ACIENDO caso omiso de lo que permanece inédito (pues no cabe juicio sobre lo que se ignora $y$ estos comentarios sólo atañen a la obra públicamente conocida), la primera vez que aparece el nombre de Manuel Toussaint ligado a un trabajo literario es en 1914, compartiendo, con Antonio Castro Leal y Alberto Vázquez del Mercado, la responsabilidad de una selección de Las cien mejores poesias liricas mexicanas. Dos años después entra de lleno en la tarea, ardua cuando se lleva con estrecho sentido de responsabilidad, de hacer selecciones de autores ilustres, vigilar sus ediciones y redactar los prólogos, todo ello para aquellos cuadernos, de feliz memoria, que publicó la Editorial Cultura desde 1916 durante varios años; luego tuvo parte muy principal en la revista y en las publicaciones de México Moderno que fue, también, loable esfuerzo; colaboró en ediciones de la casa Porrúa, de la Sociedad de Bibliófilos y en diversas empresas análogas, poniendo siempre su saber y su buen juicio en páginas de prólogos que son, muchos de ellos, estudios valiosos, que prestarian grandísimo servicio al lector inteligente y cuidadoso. Inicia estos trabajos con el prólogo y selección de las Poesias escogidas de Sor Juana Inés de la Cruz, * en 1916, prólogo muy bueno que no

* Para mayor facilidad de la lectura van aquí enunciadas las obras en que participó Toussaint sin dar los títulos exactos, que a veces son largos, ni sus referencias bibliográficas íntegras. El lector interesado en ello podrá encontrar los datos completos y exactos en la Bibliografía de Manuel Toussaint, que se publica en el St plemento de estos Anales. 
debería ser olvidado, al menos fragmentos de él deberían recogerse. en esa última parte, "Fama Coetánea y Póstuma", de las Obras Completas de Sor Juana (ahora en proceso de edición por el Fondo de Cultura I.conómica), que por fin ha venido a satisfacer aquella necesidad que en el citado prólogo: ¡ hace cuarenta años! señalaba Toussaint, en cuanto a la carencia de libros accesibles con las obras de Sor Juana y de un estudio apropiado sobre la poetisa.

El mismo año de 1916, al final de la edición que hizo Cultura de los Cuentos de Gutiérrez Nájera hay una interesante y curiosa nota bibliográfica a propósito de reciente edición, en la imprenta Ballescá, de la mejor novela de Rafael Delgado. Nada muestra mejor el criterio de Toussaint en aquella época respecto a la literatura que releer esa página que, por estar hoy tan remota de la mayor parte de los lectores, por motivos materiales y críticos, bien vale la pena reproducirla y glosarla brevemente, dice así en su parte más substancial:

"La casa editorial Biblos acaba de reimprimir correctamente esta popular novela ... [La Calandria $]. "$

"Respecto de la obra misma, nuestra crítica hablada y familiar la que recela imprimir sus juicios en letras de molde, ha determinado su mérito en la siguiente fórmula: Es La Calandria una aceptable novela; es la obra menos mala que haya surgido de pluma nacional antes de la era presente. ¡Exiguo será el caudal de nuestra novelistica de ayer, cuando no llega a contar lo que sin reticencias puede llamarse una buena novela! Porque quienes encomian la obra de Delgado recurren a cualidades secundarias como el color local -que acaso interese a los nativos de Pluviosilla-, como el buen estilo, el terso decir de un prudente académico; como la conformidad exacta entre los tipos de la novela y los personajes de la vida real; como el mexicanismo de la obra, consistente en escoger los tipos más vulgares de las clases inferiores y reproducirlos con su imprescindible dialecto.

"Pero, desengañémonos: todo eso está muy bien, mas no basta a crear lo que hoy llamamos una novela. En el siglo de La rebelión de los ángeles poco nos importa el realismo y el respeto a las tres dimensiones. Queremos una vida intensa y artística, no que copie la vida, sino que rebose la vida de si misma; queremos más personalidad en el autor; que nos dé sus propias entrañas sí es preciso, en vez de un perenne subrayado trivial. ¿Qué hay muchachas bobas que abandonan a sus novios pobres por buscar más alto y caer en poder de jóvenes libertinos! ¿Qué 
nos interesa a nosotros? ¿Era preciso escribir tan sin escrúpulo literario un libro para mostrarnos lo que a diario ven nuestros ojos?"

"Una tercera edición de La Calandria quizás venga a demostrar cuán lejos se agitan nuestras actuales inquietudes literarias, respecto de este discípulo de Pereda, que, con ser cien codos más alto que nuestro autor, ha entrado ya en un justo y soñoliento claudicar."

En esa nota el menosprecio con que trata la novela de Delgado, válido para toda la novela realista, es sin duda insolente pero justo y sigue siéndolo porque hoy en día, casi al medio siglo de aquellas palabras, ocurre que la novelística mexicana sigue, en su casi totalidad, fincada en valores secundarios y persiguiendo metas equivocadas. La segunda parte de la nota de Toussaint delata, aún más claramente que la anterior, lo que había de juvenil en su autor y la influencia que en él ejercían, entonces, las lecturas más frescas; basta parar mientes en este detalle: la nota es de 1916, es indudable que acabaría de leer, en ejemplar con la tinta fresca La Rérolte des Anges que se publicó en Francia con fecha de 1914 y no llegaría aquí antes del 15 o acaso hasta 1916, venciendo las dificultades consiguientes a la guerra; pero esa novela de France le parece a Toussaint i la novela del siglo! cuando sin duda hoy la pondriamos en lugar muy secundario aun entre las del mismo autor que, a su vez, no podemos considerar en primer término en el cuadro de la novelística occidental de los últimos cien años. Pero, con su pasión juvenil en sus admiraciones y en las censuras, yo no puedo menos de sentir gran estimación por aquella inquietud valiente que impulsa a trepar a los altares, derribar los dioses y rascarles el oro superficial hasta que asome el cobre.

Después prologa las selecciones de poemas de Julio Torri, de José Asunción Silva y de Guillermo Valencia y más tarde, en 1918, en el prólogo a El tesoro de Amiel, encuentro estas líneas a propósito del sentimiento del paisaje y del condepto que Amiel le da en cuanto a "estado de ánimo", que son en conjunto un párrafo de particular interés porque revela muy claramente la sensibilidad plástica y una intelección pictórica que, al desarrollarse, habrían de dar el claro y certero crítico que fue Toussaint; véase si no es de ello claro anticipo este trozo:

"Es preciso insistir tenazmente contra una idea muy vulgarizada: un paisaje no es una descripción. La literatura descriptiva ha muerto en el instante mismo en que una racha de ambiente invade la obra, y la famosa escuela naturalista lleva en ello también su parte de derrota. Es evidente. El ojo percibe, en el conjunto del cuadro, las grandes masas 
en una perfecta valorización luminosa y cromática y a la postre, algunos detalles característico y por ende necesarios. Todo, y es esta indispensable circunstancia en el paisaje, se baña en la suave profundidad del ambiente. Tales son los paisajes de Corot, tan simples en sus detalles como vigorosos en su conjunto, y tales han de ger por fuerza ineludible, lo mismo para las letras que para la pintura o la música, los paisajes que pretenden la distinción de ser obras de arte." (p. 7).

Buenos son, también, los prólogos en tomos de Urbina y de Agustín F. Cuenca, pero mejor aún es, en 1920, el de Los cien mejores poemas de Enrique González Martínez, cuidadoso examen, generoso, pero fiel y atinado de la poesia de ese autor, desde 1903 hasta 1920, de tal manera que no puede prescindirse sin menoscabo de este prólogo al revisar la crítica total sobre la poesia de González Martínez.

Ya vimos que desde 1916 Toussaint se habia ocupado en estudiar a Sor Juana, en realidad el movimiento sorjuanístico habia empezado un poco antes, en reivindicación de los olvidos, injusticias y torpezas del precedente academismo, pero toma gran impulso con esa vuelta a lo nuestro que produjo la revolución ; en ese movimiento sorjuanístico, Toussaint, que había sido uno de los primeros en el tiempo, también lo será en cuanto a la intensidad y calidad de sus trabajos. En 1926 el grupo "Ariel" publica un breve folleto intitulado: Poemas inéditos, desconocidos y muy raros de Sor Juana Inés de la Cruz, descubiertos y recopilados por Manucl Toussaint, esos poemas son tres sonetos, una silva y un romance (ninguno figuraba en los tres tomos de obras de la monja), en las páginas de explicación previa se dan las respectivas procedencias, todas indudables menos el soneto "Cítara de carmín que amaneciste...", que Toussaint atribuye a Sor Juana "con toda cautela", pero que la crítica posterior $\mathrm{y}$ rigurosa de $\mathrm{A}$. Méndez Plancarte ha desechado; ese breve estudio de Toussaint fue sin duda aportación considerable al mejor sorjuanismo. Su dedicación, en esos años, a las letras del virreinato da otro buen fruto: una Loa sacramental de las calles de México, escrita en el siglo XVII por Pedro de Marmolejo, y la reedición, con breve nota preliminar, de la Grandeza Mexicana, de Balbuena y en 1928 vuelve a prologar otra edición de Obras escogidas de Sor Juana: la selección es buena, ya no repite solamente los poemas conocidos sino que incluye la "Respuesta a Sor Filotea de la Cruz", señala aspectos no siempre advertidos en su obra y el prólogo contiene juicios personales que deben set entendidos en función de sus circunstancias: un deseo de reaccionar cuntra la valoración efectiva del romanticismo apoyando, en cambio, los 
valores intelectuales y técnicos que dan a la obra de arte un carácter universal y duradero, una estimación del artista que sabe hacer su obra en contra de la "inspiración" y la feliz casualidad, asi se explica este juicio de Toussaint sobre Sor Juana:

"Si tratamos de encontrar una fórmula que defina las características poéticas de Sor Juana, después de haber leído sus apasionados versos de amor, sus poemas dolientes... sus sonetos un tanto alambicados para conseguir ciertos efectos de redondez, sus villancicos áureos, sus versos jocosos, sus Loas, sus versos de ocasión que, a diferencia de lo que ocurre en la mayoría de los poetas, no por ser de ocasión dejan de ser muy estimables, encontraremos que Sor Juana en todos sus poemas obedece, no a una inspiración subyugadora, sino a una plena conciencia intelectual de su arte; en ella no hay nada de inconsciente o involuntario: todo ha sido trazado con mano segura, pensando con clara inteligencia ; todo ha sido sujeto a la propia crítica y no abandonado al azar de una musa ligera que se entrega cuando la corriente poética la arrastra en su oleaje. Llamarla poetisa intelectual parecería quizás un poco pedantesco $\mathrm{y}$, sin embargo, Sor Juana, ni en el menor de sus poemas deja de ser conscientemente intelectual. Poeta que escribió lo que quiso y como quiso y en todo lo que escribió logró realizar la intención que en ello ponía, me parece la fórmula que antes buscaba. No hay en ella tanteos, no hay vacilaciones, no hay ensayos de principiante ni versos de decadencia..."

Es fácil percibir que la posición crítica de Toussaint está plenamente acorde con la mejor y la más avanzada de su época; de seguro no otra cosa hubiese afirmado, a igual respecto, la crítica del grupo llamado de "Contemporáneos" (por la revista que precisamente entonces comenzaron a publicar), que sin duda fue el de mirada más aguda y perspicaz, el más enterado y de mejor preparación entre los que podían sentirse en la vanguardia de las letras mexicanas en aquellos años en que principiaba el segundo cuarto de este siglo, y con eso quiero significar el fresco espíritu y la posición delantera de Toussaint al relacionarlo con aquel grupo, del cual lo separaban no menos de diez o doce años de edad (casi todos los de "Contemporáneos" nacieron en los primeros años del siglo), pero al cual lo acercaban su cultura, formada en literaturas europeas $y$ el ánimo francamente moderno y renovador.

Hay un largo paréntesis de once años desde aquel trabajo sorjuanista hasta 1939 en que estudia El periodismo mexicano en los albores de la Independencia, tal hueco, sólo aparente, se llena con sus trabajos en el campo de la investigación, la crítica y la enseñanza del arte de 
México, pero nunca abandona las investigacionęs en las letras, simplemente éstas se espacian alternando con las otras intensas actividades de Toussaint.

Al año siguiente vuelve, una vez más, a guiar la edición de un "nuevo viejo" libro (cinco rarísimos folletos del siglo pasado, reunidos en un volumen), El libro de las charrcrias, por Luis G. Inclán, con un buen prólogo en que nos da, con las cualidades de síntesis que habia logrado en ese género, noticias biográficas, criticas y bibliográficas de esa original personalidad que fue Inclán. Mucho más tarde realizó un trabajo análogo, en la reedición del Compendio de la vida y virtudes de la venerable Catalina de San Jian. (Vida de la China Poblana, Ed. Xóchitl, México, 1946), pero antes, en 1940, habia publicado en la Revista de Literatura Mexicana, bajo el título de "Nuevos aspectos en la biografía de fray Manuel Navarrete", unos documentos que son de la mayor importancia y sólo la debilidad y la desmedida negligencia de ciertos tratadistas pudo dejar inadvertida tal publicación, como en el caso de Carlos González Peña, mal historiador y peor crítico, pero no así escritores cuidadosos y responsables que oportunamente tomaron nota del hallazgo de Toussaint para rectificar conceptos sobre Navarrete: J. Jiménez Rueda, en las reediciones de su Historia de la Literatura Mexicana y F. Monterde en su estudio relativo a Navarrete en Cultura Mexicana. Aspectos literarios. México, 1946.

Entre los últimos trabajos de investigación literaria que Toussaint llevó al cabo, se cuentan la Bibliografía mexicana de Heredia, en 1953 y luego, en 1954, un estudio que presentó al ser recibido en la Academia de la Lengua, demostrando la vinculación que tuvo con la Nueva España, en el siglo xvir, don Aindrés Fernández de Andrada, posible autor de la célebre Epistola Moral ("Fabio, las esperanzas cortesanas...").

Algunos otros estudios, en prólogos o colaboraciones esporádicas en revistas, pueden encontrarse en las fichas de la bibliografía de Toussaint, pero he supuesto que no sería aqui pertinente la enumeración exhaustiva de artículos cuando mi propósito es solamente mostrar las líneas generales y los aspectos preponderantes en la obra literaria de don Manuel Toussaint.

De propósito he alterado levemente el orden cronológico, dejando sin mencionar obras de 1921 y 1926 para referirme a ellas aproximán- 
dolas a otra, treinta años posterior, porque esos fueron los únicos libros que Toussaint publicó así, con unidad de volumen y no como el resto de su labor que apareció siempre en estudios incorporados a revistas o libros ajenos. Pero, mucho más que ese aspecto formal, distingue a tales libros de que en seguida trataré el ser obras más originales y personales por cuanto no son estudios críticos ni tarea de investigación, sino recuerdos de viajes, los unos y novela para niños, el último.

En 1924 publica Toussaint sus Viajes alucinados, son observaciones y recuerdos de un viaje por España que hizo tres años antes, el titulo se explica por estas palabras preliminares: “... son las impresiones de un viajero alucinado, para quien permanecieron cerradas las puertas de la Estadística ... Este libro no es de censura ni de adulación. Amo a España como es; escribo de ella, añorándola, como la vi ..."

La primera parte se refiere a "Excursiones desde Madrid", son páginas sobre Avila, Segovia, Toledo y Sigüenza, registra impresiones, eludiendo deliberadamente el análisis y el juicio de las obras de arte que, inevitablemente, atraen su atenta observación, apenas si de pasada deja

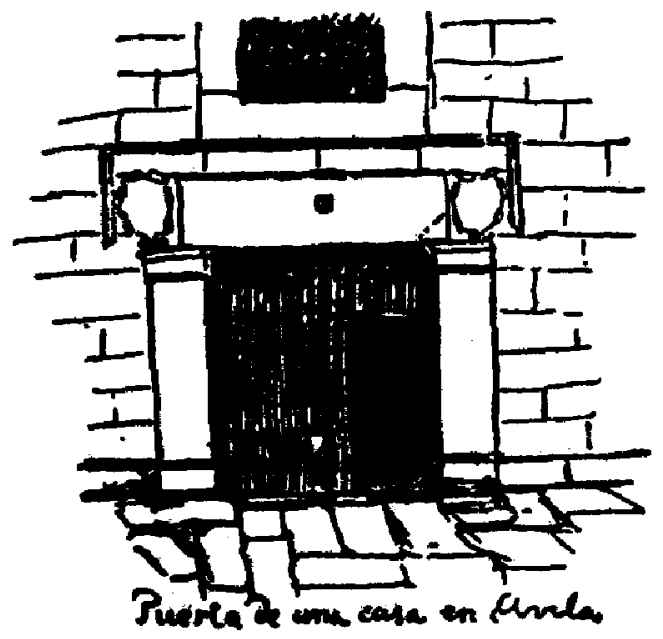

caer algún nombre: Berruguete en Avila, y alguna clasificación crítica, como en la misma Avila cuya catedral tiene un interior "románico ... en partes purísimo... en partes goticisándose..." y Santo Tomás es un "gótico moderado". De Segovia, sólo pindeladas para un apunte : el acueducto, las empinadas cuestas, el torreón del Alcázar, iglesias, un río...

El grabado que ilustra esta página y los otros dos que siguen son reproducciones de los dibujos con que $M$. Toussaint adornó sus Viajes Alucinados; el Ex-Libris que va al fimal procede de su libro Oaxaca. 
"Toledo es un juguete para los niños buenos de Madrid" que él mira fascinado y va $y$ viene por callejones, se guarda sus observaciones de monumentos y de arte, pero en cambio baja la voz y recuerda: "Yo tenía una amiga que habitaba hacia San Juan de los Reyes"... y por un breve instante alcanzamos a verlos: ella con su gabardina, sujetando su gran perro inquieto y él a su lado, señalando la encrucijada inmediata en cuyas sombras se desvanecen...; no hay confidencia, la mano que señalaba en el aire vuelve a tomar la pluma y al volver la página nos dice que Sigüenza es una "ciudad románica de piedra verde, sembrada a trechos de bloques de roca roja..." y nos asomamos al castillo, del que calla otra anécdota que personalmente le oí relatar alguna vez; naturalmente visita la Catedral y menciona el Doncel, señala su originalidad pero casi nada más, ¿ cómo no percibió su importancia de obra liminar tan extraña - para mi tan clara y precisamente-, situada en el filo de dos edades? Acaso pensó que apuntando eso se obligaría, por lo menos en algunos renglones, a las consideraciones eruditas que abundaban en las notas de trabajo, pero que quiso dejar fuera del plan de este libro.

La España del norte fue cosa de viaje aparte: Santander es menos que una estampa, en todo caso una acuarela desleída por la lluvia, pero Santillana del Mar está en varios grabados precisos y vigorosos: calles, la Torre del Merino, la Colegiata, el claustro y hasta una cosa nimia, perdurable por la emotiva evocación: "Del interior recuerdo unos frontales de plata repujada, que obsequió una familia de protectores desde México. ¡ México, plata repujada, plata en barras, plata en monedas!" Luego la caverna de Altamira, Limpias, Santoña.

De la Montaña a Galicia: Lugo "hecha de pizarra"; de Santiago no va a elogiar sólo la Catedral / claro que admira el Pórtico de la Gloria!, tmbién el pan y las legumbres merecen elogio; la posición del autor es obvia: el libro no debe registrar datos, como ya lo advirtió en el prólogo, tampoco quiere adoptar el papel de investigador, recuérdese que estamos en 1921 y Manuel Toussaint todavía está lejos de la lespecialización del historiador y del crítico y más cerca de las letras; lo hemos visto así en la cronología de su obra y él lo sabe y aquí lo confiesa en una exclamación regocijada y burlona, al terminar su visita a la Catedral: "Puerta santa de la catedral en la plaza de los Literarios ( mi plaza!)..." Pero eso no quiere decir que haga caso omiso de las artes plásticas, puesto que él fué a España principalmente para ver, estudiar y conocer sus joyas de arquitectura, de escultura, de pintura. Cierto que entonces Toussaint no había llegado a la maestría en la apreciación y en la crítica que 
más tarde alcanzó, pero ya apunta, y muy claramente, a ella cuando en un libro tan informal -en el más puro sentido- como es éste, aparece de pronto esta página, tan clara y precisa, que bien vale la pena releer:

"Toda la Catedral de Astorga parece concentrarse y expresarse en el retablo de la capilla mayor. Obra de madurez artística, de genio preciso y amplio... La distribución de las líneas generales del retablo es sobria como en un monumento clásico; los adornos que cubren los miembros arquitectónicos del edificio van aligerándose hacia arriba y en cada compartimento los grupos se distribuyen con independencia completa. Basta mirar las cuatro mujeres recostadas que adornan la parte inferior, para comprender que tenemos delante a un artista de genio: su sencillez, la amplitud de su gesto y de su línea, la fuerza con que están caracterizados sus modelos hacen pensar un poco en Miguel Angel, y lo mismo las figuras simétricas que en los cuatro remates de los compartimentos inferiores, recuerdan los de los sepulcros famosos. La pintura de esta talla es admirable de armonía y de realismo: hay que ver los henchidos senos de esta Caridad, palpitantes bajo el hambre de las bocas que los exprimen y que podrian, si quisiesen, amamantar a todos los niños desvalidos del mundo. El tiempo parece haber enverdecido un poco la entonación general del retablo que se halla así más acorde con esta triste nave solitaria de piedra, que acaso también estuvo pintada de verde. En las pilastras que limitan el retablo, en el sentido paralelo a la nave mayor del templo, dos medallones enseñan la fecha de la obra: «Acabóse año de 1575». Su autor fué Gaspar Becerra" (pp. 81 y 82).

León, Zamora, Ciudad Rodrigo y algunos pueblos leoneses y castellanos quedan allí con una ojeada a sus vitrales, al plateresco salmantino y a la cátedra de fray Luis, con el inevitable "Deciamos ayer...", pero más abundan las instantáneas costumbristas casi siempre con toques irónicos: observa que los charros salmantinos I usan bastón! por las vatas que comúnmente empuñan pero, es claro, comenta Toussaint, eso es porque son charros de a pie, mientras que los de México son charros de a caballo. $Y$ el tono satírico se combina, a veces, con las observaciones críticas, y porque líneas arriba copié una larga referencia un tanto erudita, conviene reproducir aquí esta otra página de Toussaint, por contraste, para que entre una $y$ otra el lector alcance a entrever el tono del libro que comento; habla don Manuel de la Catedral de Zamora:

"Nada tan interesante como la labor de talla del coro. Aún no se estudia detalladamente, que yo sepa, este aspecto especial de las sillas de coro, esta formidable caricatura escultórica. En cada respaldo, en cada 
pilastra, en cada ángulo, hasta en la misericordia de cada asiento, están nimiamente esculpidos infinidad de frailes $y$ monjas en posturas ridículas, con semidesnudos cómicos, en parejas que se entregan a las más descaradas obscenidades. Era la protesta por la liviandad de costumbres a que habían llegado los frailes y la venganza que tomaba el clero secular de la protección concedida por los reyes a los regulares, expresadas por la gubia de un artista nervioso: Rodrigo Alemán" (p. 106).

En la Catedral de Ciudad Rodrigo, "gótica con reminiscencias románicas" encuentra la inscripción sepulcral "casi de un paisano": "Aqvi jaze d. $\mathrm{R}^{9}$ Pco. Osorio, Marqves de Zeralbo. Virey de la Nva. Espa... Fallezio en Flandes en la ziudad de Brvselas a 14 de henero. Año de $1640 "$ (p. 150). Mas no sólo por el arte y la historia visita las iglesias: "Adelante estaba otra plaza, en una cuesta. Una iglesia la cierra frente a anchos portales. ¿ Fué aquí donde ó misa, incitado por la más bella habitante de Ciudad Rodrigo? Su paso menudo la delataba de lejos, el velo sobre su rostro picaba curiosidad y toda ella concluía por hechizar cuando al fin podía vérsele" (p. 152).

Pero esa muchacha velada y cautivadora, como la misteriosa amiga de Toledo, como el amigo que lo acompaña a visitar los bisontes prehistóricos de Altamira, son todos siluetas, casi sombras que apenas un instante apercibimos junto al viajero alucinado. En cambio, dos figuras se perfilan en la parte final del libro y en torno a ellas unos episodios que, si los hubiese querido engarzar y aderezar un poco, le habrían dado un relato (story, nouvelle) que, en esquema, es así :

En Zamora encontró a Ravenez: "Alto y grueso, de una pieza, rostro vulgar, ojos pequeños que parecen no ver, manos enormes como las del Creador del universo... La clave de aquel hombre opaco .y grande era su risa. En ella se escapaba su verdadero espíritu, rehacio a salir por los ojos..." Por ese carácter jovial trabaron amistad que luego produciria una pequeña aventura y por eso, al presentarlo, añadía Toussaint: "Yo ignoraba - icaro Ravenez! que mi vida iba a interferirse con la tuya, que ibamos a convivir por los pueblos remotos cuya existencia me revelaste..."

Pues estos dos disímiles y recientes amigos llegan a Salamanca, y al día siguiente, en casual encuentro, Ravenez sorprende con aire conminatorio a Toussaint, urgiéndole: "Apenas tenemos tiempo de tomar el tren para Béjar. Mañana es la fiesta en Candelario." Parten precipitadamente, dejando Toussaint su equipaje en el cuarto de su hotel por 
tres días (el domingo siguiente es la feria y el cuarto o lo desocupa o le costará un ojo de la cara), y en Béjar la noticia fatal : ¡ la feria de Candelario se ha aplazado! Pero Ravenez conoce el país como sus manos - sus enormes manos - y por la noche, en que comparten el cuarto del hotel pueblerino, recuerda que en un pueblo de la Sierra de la Peña de Francia, Miranda del Castañar, se celebrará la fiesta al siguiente día. "Los trajes de los habitantes eran interesantísimos, casi tanto como los de Candelario..." Había que ir a Miranda del Castañar. El medio de transporte era un viejo Ford con una carrocería de ómnibus improvisada. En Miranda presencian el cortejo de "La chica del Ramo", con tamborilero, las mozas enjoyadas y con sus vestidos tradicionales y Toussaint logra fotografiarlas gracias a Ravenez, conocido y estimado en el pueblo de tiempo atrás.

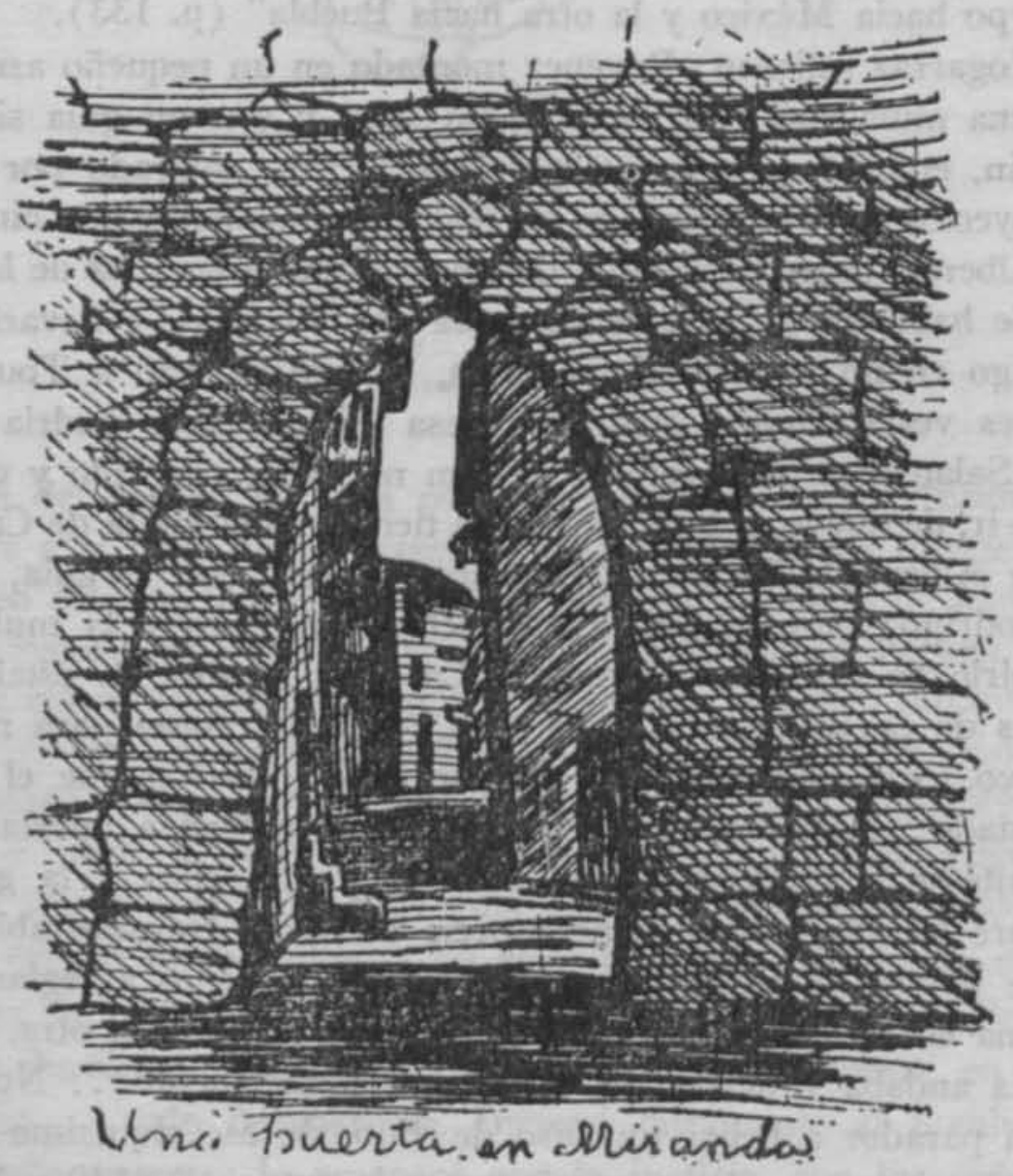

Pero no hay tiempo que perder y esa misma tarde salen para Mogarraz. La caminata, a pie porque los caballos de Miranda estaban de 
fiesta, fue de muchas horas y a medio camino toparon con "un hombre largo y canijo" que se constituyó en su guía y que muy pronto comenzó a dejar sentir su nefasta influencia llevándolos a pernoctar en una hostería de sus parientes donde todo fue amabilidades de palabra e incomodidades de hecho: alli comenzó para Toussaint una inesperada sucesión de penalidades que, por otra parte le harían imborrable el recuerdo de aquellos pueblos. Cual ocurre siempre, las penalidades en tierra ajena avivan el recuerdo de la propia y en esa noche de Mogarraz momentos hubo en que don Manuel se sintió medio descuartizado pero en las más altas cumbres de la patria: "Mi colchón tenía dos montañas en el centro, exactamente como mis amados volcanes patrios, el Popocatépetl y el Ixtaccíhuatl. No podia acostarme en ninguna de las dos vertientes, por la inclinación; acabé por tenderme oblicuamente entre ellos, con una parte del cuerpo hacia Méxiço y la otra hacia Puebla" (p. 133).

De Mogarraz salieron: Ravenez montado en un pequeño asno, Toussaint en una mula con albarda pero sin silla, y con un guía sin par en lo charlatán, embustero y lenguaraz. Este pícaro, enterado por Ravenez de los proyectos de Toussaint, se ofreció a acompañarlo por cinco duros desde la Alberca, lugar próximo a donde llegarian a las diez de la mañana y en donde habriase de separar Ravenez por dos días, y llevarlo a Ciudad Rodrigo en no más de cinco horas, lo cual pareció a Toussaint de perlas, pues vería Ciudad Rodrigo y esa misma tarde podría regresar en tren a Salamanca para ver lo que aún no había conocido y estar listo para luego ir, de nuevo, a Béjar y estar a tiempo en la fiesta de Candelario.

De la Alberca salió pues Toussaint, ya solo con el guía, rumbo a Ciudad Rodrigo; pero el guía había bebido no poco y la mula... eso hay que oirlo de testimonio directo: "La mula aquella no estaba avezada a viajes de ese género. A cada paso volvía la cabeza para morderme los pies; yo tenía que castigarla con un recio chirrión que el guía me había prestado... Dieron las once y el calor empezó a apretar bajo el sol... Quitéme la americana y el chaleco, y con ellos y la gabardina, atados sobre la silla, hicimos una especie de diván transportable, de palanquín de Virrey de la India; pero antes de podernos arreglar bien, se me caía una cosa cada minuto y a veces varias, una tras otra, de modo que el guía andaba y desandaba el camino cómicamente... Nos detuvimos en un parador a beber un vaso de vino, de ese riquísimo vino que dejaba su aroma y su color y continuamos la ruta..." (139 y 140). Así llegaron al Parador del Tordo, en el Maíllo, donde Toussaint confiesa que él era la única nota discordante y exótica con su "indumentaria ultra- 
civilizada", en medio del grupo que alli comía, entre ellos un habitante de las Hurdes a quien todos criticaban y embromaban; el almuerzo era malo pero el vino era magnífico y " $\mathrm{El}$ compadre guia, a fuer de conocido y conocedor, con un guiño había pedido del bueno, se alegraba cada vez más..." (p. 143). Con un calor excesivo siguen la marcha, en Morasverdes otro descanso y otros tragos que el guía se echa al coleto y la mula cada vez más rehacia para caminar. A las tres de la tarde llegaron al Tenebrón, Toussaint increpaba al guía recordándole que a esa hora ya deberían estar en Ciudad Rodrigo, el guía echaba la culpa a la mula y para

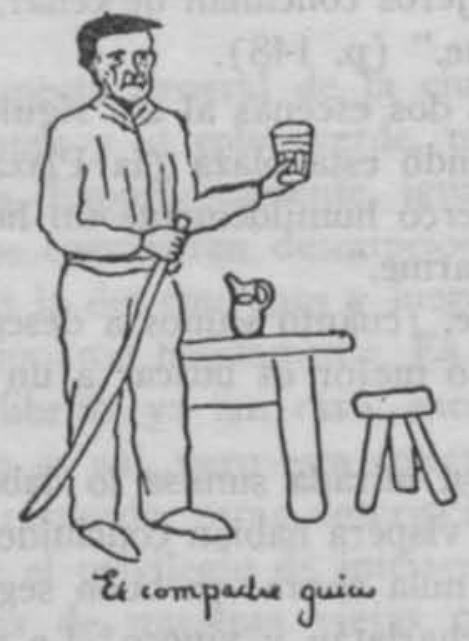

consolarse del regaño en cada parador seguía bebiendo. "Entonces (naturalmente a la hora de lo irremediable), comprendi en la que me había metido: no sólo no llegaría a Ciudad Rodrigo a tiempo de tomar el tren para Salamanca, sino que podía considerarme feliz si llegaba. En Salamanca me cobrarian un potosí por la habitación ocupada durante la feria, y adiós cita con Ravenez en Béjar, fiesta de Candelario, todo..." (p. 144). Pasado Cilleruelo y otros lugarejos apareció, muy lejos Ciudad Rodrigo y poco después "La difícil caminata volvióse imposible: yo tenía que arrear a la mula y al guía que cada vez se quedaba más a la zaga. De pronto se encendieron las luces de Ciudad Rodrigo; menos mal, pensé para mí; mientras vea las luces no puedo perderme. Pero aquella esperanza duróme poco, pues al concluir de bajar la cuesta, en un recodo del camino... todo desapareció. Increpé duramente al hombre que ya apenas podia tenerse; lo amenacé con la justicia, con los señores de la embajada, con representaciones diplomáticas, con una guerra internacional; todo en balde. Y lo peor es que la mula, en odiosa solidaridad con 
su amo, se negaba rotundamente a caminar si él no iba delante. Aqui lo más terrible sería perder el camino pensaba yo, y en efecto, pude darme cuenta de que ya lo habíamos perdido: estábamos en medio de un gran sembradío; el hombre buscaba de aquí para allá, cayéndose, la mula, monolitica, no se movía. Fueron cinco terribles minutos: la noche había cerrado... Por fin me decidí a continuar a pie, buscar el camino, y si no llegaba a Ciudad Rodrigo, al menos encontraría sitio menos inhospitalario..." (p. 145-146).

$\mathrm{Y}$ así llegó a Ciudad Rodrigo, a pie... "Encaminéme al hotel y llegué a tiempo que los viajeros concluian de cenar, pero aún hubo para mí. Eran las diez de la noche." (p. 148).

El epílogo son estas dos escenas al día siguiente:

"Absorto estaba viendo esta plaza (la Plaza Mayor de Ciudad Rodrigo) cuando se me acercó humildemente un hombre: era el arriero de marras que venía a cobrarme."

"-Muy bien, le dije, ¿cuánto vamos a descontar por no haber cumplido su compromiso? Lo mejor es buscar a un guardia civil para arreglarnos con él."

"Nada contestaba; su mirada sumisa lo daba por vencido; me mostró sus alpargatas que la víspera habían concluído su existencia útil. Toda la ira sentida antes, era nula ahora: I a buen seguro que iba yo a perjudicar al pobre hombre, charlatán y vinoso! Le pagué sus cinco duros y le dije que lo único que deseaba era no volver a verlo..."

"Regresaba en santa paz al hotel cuando volvió a alcanzarme el guía de la víspera. Con los cinco duros había hecho su agosto: botas de baqueta fuerte, cinchos nuevos para la mula, qué sé yo. Finalmente había comprado un gran melón y. quería regalármelo. Riéndome para mi sayo, dejélo con su regalo y le repetí que no deseaba verlo más." (p. 152).

Más tarde regresa Toussaint y visita la ciudad y la región salmantina y de repente, en Oropesa, vuelve a topar con Ravenez y juntos prosiguen a Talavera de la Reina; alli lo vemos un rato más hasta que por último lo perdemos de vista al bajar del tren en Madrid, porque Ravenez vive cerca, en las Delicias, y Toussaint, gozoso de encontrarse nuevamente en tierra conocida, "en casa" se encamina a su cuarto de pensión, en el centro de la ciudad, para digerir sus pequeñas aventuras de "la conquista de Ciudad Rodrigo" y apuntarlas en su cuaderno de notas de donde salieron, luego de bien cernido el grano y aventada la paja, esos $V$ iajes alucinados, su primera obra formal y cuajada, salida de las prensas de la Editorial Cultura en México, a fines de mayo de 1924. 
En 1926, Toussaint escribió y publicó Oaxaca. Es un precioso librito (126 páginas de $12.5 \times 9.5 \mathrm{cms}$.) cuyo valor aumenta con los diez y ocho grabado en madera (16 camafeos y 2 a una tinta) de Francisco Díaz de León. El libro sigue la misma trayectoria de enfoque y de estructura que Viajes alucinados, con las diferencias naturales y necesarias porque este último se refiere a viajes de muchas semanas mientras que el otro es, en verdad, una impresión emocionada de diez diaz de permanencia en Oaxaca.

Comienza por el aspecto general de la ciudad: lo recio y achaparrado de las construcciones y el color verde, más vivo aún después de la lluvia, de sus piedras. Esporádicamente, igual que en las páginas de los Viajes alucinados, se encuentran descripciones más detalladas, entre los grandes trazos, como la del convento y luego la del templo de Santo Domingo, que le impresionaron hondamente. Es probable que el lector en cuyas manos caiga ese librito, ya tan raro, encontrará frescura en tales descripciones y sin duda es así, pero esta relectura me ha hecho evocar, acaso enaltecidas en el recuerdo, otras descripciones más coloridas y vibrantes, porque yo tuve el privilegio de iniciarme en el conocimiento de las joyas arquitectónicas de nuestras viejas ciudades no leyendo sino oyendo las palabras de don Manuel y allí, en la cátedra o en la simple charla, las explicaciones tenían una vida, una vivacidad, que rara vez pudo alcanzar el propio maestro en sus escritos. $Y$ ya que he aludido a sus cursos cabe aqui una breve apostilla: tratando de los conventos oaxaqueños dice que: "La Soledad pertenece al tipo de iglesia conventual de monjas, definido en el siglo xvir" (Oaxaca, p. 40), pero no es así, la Soledad no es una iglesia del tipo de convento de monjas pues el mismo Toussaint nos enseñó, años después de escritas aquellas líneas y ya con la madurez y Ia depuración de su propio saber, que el tipo de tales iglesias monjiles carece de puerta frontal puesto que el pie de la nave la ocupan los coros alto y bajo y la entrada o entradas para el público son siempre laterales.

Toda la arquitectura oaxaqueña es baja, fuerte, con gran predominio del muro sobre los vanos, para defenderse de los terremotos. Las casas son simples, sencillas, algunas de ellas señoriales, suelen tener arcos de diversas curvas al interior del zaguán, pero hay variantes. "Claro que no todas las casas viejas son iguales. Recuerdo la portada de una completamente clásica, bajo bárbara capa de cal; una trabe adintelada, dos 
medallones con relieves de busto: parece una portada de Avila..." (Op. Cit. p. 25.)

Menciona con elogio las castizas joyas de oro y aljófar y esas otras, menos brillantes pero acaso más artísticas, los hierros en ventanas, balcones, canceles, ya tan perdidos en estos días; también el capítulo de comida es una laudanza y eso que, en tan breves días, no alcanzó a saborear la indescriptible riqueza de la cocina oaxaqueña que sale de esa otra cosa admirable, el mercado que, ese sí, pudo apreciar el viajero en todo su bullicio y colorido y del cual justamente dice "Este mercado de Oaxaca, en sábado, me parece el mercado más igual a los tianguis que describen los conquistadores en sus relaciones..." (Op. cit., p. 75.)

Dije antes que Oaxaca no es un estudio de arte colonial como los que más tarde escribiria Toussaint, sino que está en la misma línea de sus Viajes de España y se le pueden aplicar las mismas palabras iniciales de aquéllos: "... son las impresiones de un viajero alucinado....", y por ello también surgen, en líneas aisladas y hasta en largos párrafos, flores de un lirismo personal y emocionado. "La vida en Oaxaca se desliza apacible y grata..." y en el ocio espléndido de los atardeceres, sentado a la mesilla al aire libre (el autor habla de la "terraza" como de un café europeo) Toussaint se siente más joven, más audaz "y hasta con algo de romanticismo..." (p. 12); algo y aun algos, por cuanto en el romanticismo hay de actitud sentimental y evocadora, que va creciendo en el alma del viajero a la vista y deleite de la preciosa ciudad, y de repente se desborda en efusión lírica por la novia perdida que le revive en la bella escultura de la Virgen de la Soledad:

"Tengo un secreto, Virgencita de la Soledad, pero no sé si al revelarlo incurra en falta. Virgencita de la Soledad, eres el vivo retrato de una novia que yo tuve. Tenía, como tú, alargado el rostro, tal una princesa de la casa de Austria; sus ojos miraban como los tuyos; sus manos; igual que las tuyas, sus manos que yo besaba embelesado, eran de una belleza, de una suavidad de azucena. La azucena de oro que tienes en tus manos benditas no es tan bella como tus mismas manos, como las manos de aquella novia que yo tuve y perdi, en el laberinto del tiempo y de mis viajes..." (Op. cit., p. 53-54.)

Y también, al final, un adiós del viajero a la ciudad que lo cautivó no sólo en su interés objetivo sino también en la impresión afectiva. Lástima que el autor no haya puesto más cuidado, más cultivo, en el manejo de las formas literarias; porque hay que decirlo, puesto que sin ser estas lineas una crítica substancial sí es preciso apuntar valores y de los 
positivos van ya múltiples referencias, cierto es que Toussaint usa generalmente el idioma como un puro instrumento útil para transmitir ideas o datos, es decir conocimientos, y muy pocas veces intenta comunicar emoción, por eso es particularmente interesante ese aspecto lírico, escaso en su obra, y por eso yo he querido hacerlo destacar en estas páginas; pero en uno y en otro caso: objetividad o lirismo el estilo es pobre; el lenguaje es claro y directo pero sin carácter y en ocasiones hay manchas obvias: repeticiones innecesarias que denotan descuido o pobreza de léxico, ciertos errores de sintaxis, hiatos, palabras unidas de ingrata manera como esa línea arriba citada: "bajo bárbara capa de cal", decasílabo de indudable cacofonía. Mas tampoco hay que juzgar el todo por tales tropiezos; yo simplemente señalo que la forma, en los escritos de Toussaint, no está cuidada y es curioso que no pusiera mayor empeño en escribir bien, a pesar de su evidente amor y conocimiento de las bellas letras.

La novela para niños, a la que aludí en párrafo precedente, es la que apareció, en 1954, con este título: Las Aventuras de Pipiolo en el Bosque de Chapultepec. Relato para niños escrito por Santos Caballero. En su aparición fue escasamente comentada, seguramente porque a los encargados de las ordinarias reseñas de libros no atrajo la atención ni el asunto ni el autor, del todo desconocido (salvo uno o dos breves comentarios de alguien acaso previamente advertido) pues no alcanzaron a percatarse de que esa firma "Santos Caballero", era casi literalmente la traducción de los dos apellidos de don Manuel Toussaint Ritter, otro juego más en un libro que es todo juego: en el asunto, en las ideas, en la forma.

Don Manuel me envió un ejemplar del libro diciéndome que eran sus "primicias novelísticas", yo le contesté (desde Guanajuato, donde por entonces me encontraba) escribiéndole que mucho admiraba que hubiera él empezado por lo más difícil: la sencillez. El libro todo es bueno: el interés se mantiene siempre; los personajes, que son en su mayor parte los habitantes del bosque, están vivos y algunos, los principales, tienen verdadero y propio carácter como también, en breves rasgos, el velador y el ciego y Pipiolo, el héroe, dentro de su convencionalismo.

El ambiente es magnífico y qué bien que se hayan escrito esas páginas sobre nuestro hermoso Chapultepec, tan desdeñado como tantas otras cosas nuestras, por la imbecilidad de esa nuestra actual novelística, sórdida y obsesionada en considerar que los únicos ambientes posibles son 
los arrabales de la ciudad o los más remotos lugarejos en lo más desierto del altiplano o en lo más inaccesible de la selva tropical. $\mathrm{Y}$ en cuanto al ambiente de Pipiolo, ¿cómo es que sabe usted tantísimo de ornitología?, preguntaba yo a don Manuel, y él reía con su risa sin ruido pero que le subía por todo el cuerpo y salía por el gesto y los ojos.

Entre los pájaros y las hormigas, en el ir y venir por las rocas y los árboles van cayendo las ideas y alumbrando los sentimientos, de acuerdo con la índole y el propósito del libro; de tanto en tanto las finas pinceladas de las burlillas a costa propia $y$ hasta algunos toques de crítica (que el niño lector no advertirá pero que el autor dejó caer en su juego) como la alusión accidental a las Cartas de Lord Chesterfield.

¿Qué pena que tales "primicias novelísticas" hayan quedado alli, sin continuación ni desarrollo!

El último trabajo sobre literatura que realizó Toussaint fue la serie de conferencias que pronunció en El Colegio Nacional, en 1955, acerca de la novelista inglesa Jane Austen y su obra. La pregunta inmediata, al menos para mí, es ¿ por qué interesarse precisamente por Jane Austen? Si tenemos en cuenta que la obra precedente fue una novela para niños, acaso no sea descaminado suponer que Toussaint, en estos años recientes, que fueron para él los últimos, se sentía atraído por lo claro, lo simple, lo fresco y que, por eso, gustó tanto que decidió comentarla en un ciclo de conferencias, una obra llena de esas vidas tan de todos los días que Jane Austen creó en su "lucid, cool, sub-ironical prose", como dice Entwistle.

Por este comentario, que no crítica, de trabajos literarios de Toussaint se verá que ellos no fueron ni pocos ni esporádicos sino que forman una parte muy considerable de la producción total que su bibliografía contiene, y acaso de mayor importancia aún en su íntimo ser intelectual pues aunque en el último tercio de su vida, de 1934 a 1955 aproximadamente, su ocupación más constante fueron los problemas históricos y críticos del arte mexicanos, en sus expresiones de las grandes artes plásticas, por lo cual su nombre alcanzó justa consagración en el campo de esas disciplinas, sin embargo de todo ello jamás olvidó su primitivo entusiasmo por las cuestiones propiamente literarias y los frutos de esa tarea, 
de hecho incesante, se eslabonan y aparecen a lo largo de más de cuarenta años hasta el fin de sus días de modo, pues, que no se tendría nunca una visión apropiada ni se podría formular un juicio acertado de Manuel Toussaint sin conocer y reconocer lo que produjo en el campo de lo literario ya como investigación y crítica, ya como impulso a la difusión, ya como obra de invención y particular creación.

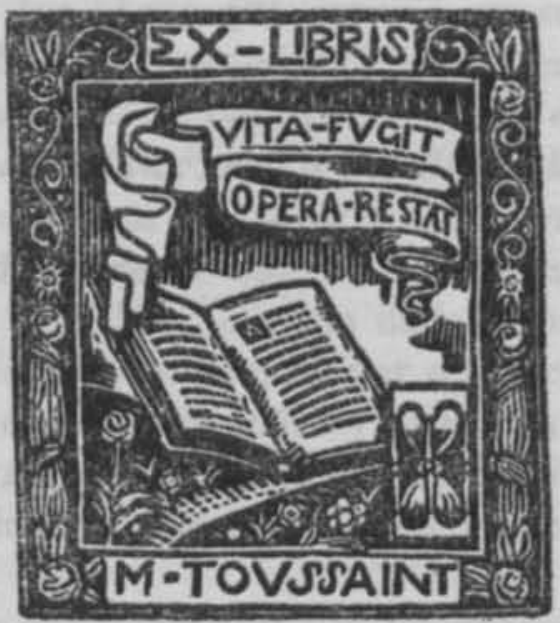

